we know little of the effects of descending tracts, probably mainly reticulospinal on phasic and static fusimotor neurones.

Finally we must be cautious in applying results from cats directly to man. It is well known that the corticospinal tracts end in interneurones in cats, and few if any fibres end directly on motoneurones. This is not so in monkeys, in whom a large number of corticospinal fibres end on motoneurones, and presumably the same is true in man. The distribution of 'disuse atrophy', to use the old term, may well be different in cats and man. While therefore our present knowledge of mechanisms of spasticity in spinal man is incomplete, there is every reason to hope for a flood of exact information in the near future.

\title{
REFERENCES
}

BARker, D. (1962). In: Symposium on Muscle Receptors, ed. Barker, D., pp. 227-240. Hong Kong: Hong Kong University Press.

Cooper, S. (196I). Quart. F. exp. Physiol. 46, 389.

Denny Brown, D. (1966). The Cerebral Control of Movement. Liverpool: University of Liverpool Press.

Eccles, R. M. \& Lundberg, A. (1959). F. Physiol. 147, 565.

McCouch, G. P., Austin, G. M., LiU, C. Y. (1958). F. Neurophysiol. 21 , 205.

Matthews, P. B. C. (1964). Physiol. Rev. 44, 2 I9.

PerL, E. R. (I958). F. Neurophysiol. 21, IOI.

Teasdall, R. D., Magladery, J. W. \& Ramey, E. H. (1958). Fohns Hopk. Hosp. Bull. ro3, 223.

Teasdall, R. D., Villablanca, J. \& Magladery, J. W. (1965). Fohns Hopk. Hosp. Bull. 116229.

Van der Meulen, J. P., Gilman, S. \& Denny Brown, D. (1966). Nobel Symposium: Muscular Afferents and Motor Control pp. I39-I49. Stockholm: Almquist \& Wiksell.

\section{SOME STUDIES ON THE PATHOPHYSIOLOGY OF SPASTICITY}

\author{
By Geoffrey Rushworth, M.A., D.M.
}

The Department of Clinical Neurophysiology, Churchill Hospital, Oxford

MuCH of our understanding of the nature of spasticity has been derived, in the first instance, from experimental work in animals, and it will be necessary to describe briefly some of this before I describe the approaches which we have made to this subject in the human patient.

The experiments of Sherrington (I898) on the origin of decerebrate rigidity in the cat and monkey were an important starting-point. These experiments drew attention again to a curious phenomenon of muscular rigidity which had been observed by Magendie and others and which appeared within a few minutes of severing the brain-stem in many animals. Sherrington demonstrated its dependence upon sensory input to the central nervous system, not from cutaneous receptors but derived from the stiff muscles themselves, so that when appropriate dorsal roots were divided the muscular rigidity was locally abolished. Muscle spindles were already known to be present in skeletal muscles, and, a few years earlier, Sherrington (I893) himself had shown that they were sensory organs. We will 
return later to these rather complex sensory organs, for recent work on them plays an important role in my story.

The posture of the decerebrate cat or monkey was essentially one of extension of the limbs, of the head and neck and tail, a condition that Sherrington described as exaggerated standing, for in these animals, with their quadrupedal progression, the extensor muscles are the anti-gravitymuscles. Manipulation of the limbs showed that the muscles put up a resistance to displacement, greater when the extensors were stretched than the flexors, but indisputably present in the latter as well as the former. The resistance generally tended to be plastic, that is, the limb assumed more or less the new posture imposed upon it. This was true rigidity, and in this form it was usually found that the tendon reflexes, though brisk, were not greatly exaggerated or clonic. The decerebrate state, however, was not a constant state, it

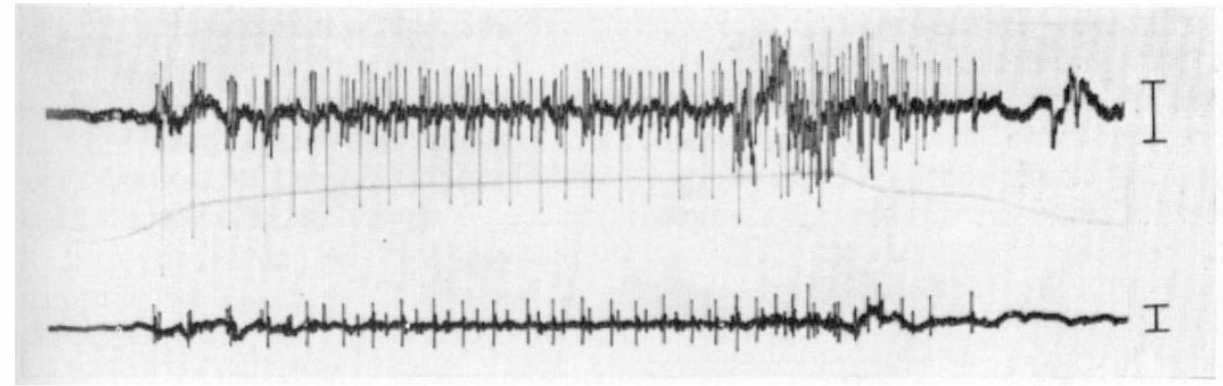

FIG. I

Electromyograms from lateral (upper) and medial (lower) leads of gastrocnemius in a patient with spastic diplegia. Mechanograms of muscle stretch (middle line). Progressive slow stretch of muscle produces recruitment of units and later acceleration until the lengthening reaction occurs (dipon mechanogram) and there is electrical silence. From Rushworth, G. (1960). Spasticity and rigidity: an experimental study and review.

f. Neurol. Neurosurg. Psychiat. 23, 99.

varied from one animal to another, and even from one moment to another, probably due to the anatomical inconstancy with which the neuraxis could be severed, to local haemorrhage within the brain stem which could increase further the deficit of function, to biochemical changes of electrolytes or of blood glucose which often shows a spectacular rise following a lesion of this part of the brain-stem, and to other difficulties over which the experimenter had little or no control. One variation of the decerebrate state was shown by those animals whose posture was of extremely stiff standing, so that they appeared to be standing on their toes. Manipulation of this animal's limbs showed that, though the resistance to stretching resided principally in the extensor muscles, the resistance was not plastic but increased steeply as the muscles were stretched until, at a certain limiting-point and quite suddenly, the resistance ceased and the limb folded up to assume the posture imposed upon it. In addition, the extensor tendon jerks were extremely brisk and clonic. Clearly this condition is identical to the spasticity which occurs in human patients following disease of the central nervous system-spasticity of limbs being manifested by the increased resistance to passive stretch especially in one direction of stretch, and following the large build-up of resistance, the lengthening reaction terminating it (fig. I). 
Foerster (I9I I) quickly applied to human patients Sherrington's demonstration that dorsal root section abolished decerebrate rigidity. In spastic children, Foerster sectioned alternate lumbar dorsal roots, greatly relieving the spasticity so that many of these children were able to walk for the first time. The consequent sensory denervation, even with alternate root section, was, however, believed to be disadvantageous and Foerster's courageous and pioneer work has, so far as I know, never had proper appraisal.

The work of Liddell and Sherrington (1924) clarified the nature of decerebrate rigidity. The increased resistance of muscles to stretch was an overactive stretch reflex, a reflex which in the normal animal was at least partly responsible for its posture. By framing it in these terms, it then becomes a necessary and obvious step to enquire into the sensory end-organ which would respond to stretch, the afferent pathway, the central organisation and, finally, the efferent pathway and its distribution. In the event, it took many years and many different techniques to answer some of these questions.

Liddell and Sherrington found that the speed of stretching a muscle was clearly important to the size of the reflex response. Sudden stretch of a muscle, by say, $8 \mathrm{~mm}$. was followed by a large peak of tension which subsided to a plateau even though the muscle was steadily elongated (fig. 2). They called the peak of tension,

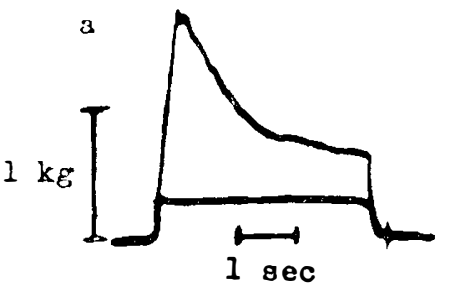

$\mathrm{b}$

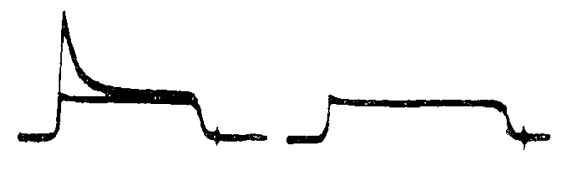

FIG. 2

Isometric myograms from the soleus muscle of a decerebrate cat. Each record shows the tension response to a sudden stretch of $12 \mathrm{~mm}$. which is held for about three seconds before being suddenly released. The myogram of the completely denervated muscle is superimposed on each record. (a) Large phasic (peak) and static (plateau) stretch reflexes. (b) Ten minutes after 0.2 per cent. procaine applied to the nerve. The phasic reflex is reduced, but the static has been abolished. (c) Complete inhibition of both phasic and static reflexes by stimulation of central end of ipsilateral lateral popliteal nerve. (From Rushworth, G., Muscle tone and musclespindle in clinical neurology. In: Modern Trends in Neurology, Ed. D. Williams. London: Butterworths, 1962.)

the phasic stretch reflex, which was seen in more pure form as the tendon jerk, and the plateau, the static or tonic stretch reflex, which was clearly suitably adapted for maintaining posture. This separation gradually became obliterated in time, but I believe that it is a useful one and one which may represent two clear aspects of muscle spindle activity-one largely dynamic responding during the change of muscle length and its discharge being proportional to the rate of change of length, and one largely static responding when the muscle length is increased and maintained at increased length. The discharge of this type of receptor is simply proportional to the actual extension of the muscle (Jansen and Matthews, 1962; Matthews, I962). It is a commonplace observation that posture is abolished 
during the early stages of barbiturate anaesthesia, the muscles are flaccid, yet the tendon jerks are still present. A similar state of affairs may be seen in human cerebellar disease which produces hypotonia without loss of tendon jerks. Occasionally, disease of the central nervous system is followed by very brisk and clonic tendon jerks, though the resistance of muscles to slow stretch is little increased, and the reverse of this, intense spasticity with small tendon reflexes, may occasionally be seen. It is, therefore, convenient to think of the phasic and static stretch reflexes as separate functional entities, with duality of central control, which can be interfered with independently by diseases of the central nervous system, but it must be admitted that, as yet, there is no clear evidence to link them with the dynamic and static discharges of muscle spindles (though this is probable) nor with the phasic and tonic motoneurones that have been identified by Granit (1955) as the motoneurones which predominantly (but by no means exclusively) supply fast and slow muscles respectively in the cat.

It might be argued that the hyperactive stretch reflexes that follow the classical type of decerebration are not the same as those which are found after other lesions of the central nervous system. Denny Brown and Liddell (I927) found that the heightened flexor reflex activity which followed acute spinal transection in the cat and dog gave place, in the course of time, to extensor rigidity which in the dog especially became so intense that standing was possible. Even chronic isolation of a very few spinal segments, was followed by rigidity of the muscles innervated by this level, and this spinal rigidity was abolished by section of the appropriate dorsal roots. Extensor muscles, particularly, showed the same increased phasic and static stretch reflexes as in the decerebrate preparation, and these had the same qualitative behaviour to ipsilateral inhibition and to deafferentation. In addition, these experiments showed the sole dependence of the stretch reflex on the spinal cord and the restriction of its spinal pathway even to a single spinal segment. Many years later, Cohen (1953) showed that the stretch reflex is an intensely local affair; stretch of one muscle-head, or even a fragment of the muscle-head, results in a reflex response limited to this fragment.

The work of Pollock and Davis (I923-30), however, seemed to conflict with the experiments of the Sherrington school. Pollock and Davis had aimed at producing a decerebrate preparation with a minimum of surgical trauma, so they developed the method of tying a ligature around both carotid arteries and the basilar artery at the level of the pons. This resulted in an intensely rigid preparation, which, however, was not very reflexly active. Crossed extension reflexes were rather feeble, as was ipsilateral inhibition, but the neck turning reflexes of Magnus and de Kleyn were well shown. Tendon jerks were not exaggerated or clonic and sometimes were difficult to elicit against the background of continuous muscle contraction. Unlike the classical Sherrington preparation, section of dorsal roots was almost without effect on the rigidity, but, on the contrary, the rigidity disappeared if the vestibular nerves were sectioned.

At that time it seemed almost inconceivable that there should be any fundamental difference, other than operative technique, between the Pollock and Davis animal and the classical Sherrington preparation, but work in Granit's laboratories (Granit, I955) showed that, in fact, the two preparations differ anatomically, as the Pollock and Davis procedure produced infarction of the anterior lobe of the cerebellum as well as the fore-brain, whereas the former is intact in the classical 
Sherrington preparation. The rigidity of the Pollock and Davis animal is controlled by the labyrinths and is therefore relatively independent of the dorsal roots. The rigidity of the classical Sherrington preparation is dependent on the discharge of muscle spindles within the rigid muscles themselves, but it could be converted into a labyrinth driven rigidity by the simple expedient of cooling the anterior lobe of the cerebellum (Granit et al., I955).

When I began my work on human spasticity and rigidity I had in mind to investigate the muscle spindle or the labyrinthine contribution to these states, but, in the event, I found that the muscle spindle contribution to the afferent influx appeared to be the dominant factor in the majority of clinical states of either rigidity or spasticity (Rushworth, I960) except for terminal dystonia.

It becomes necessary, therefore, to examine the muscle spindle in more detail so that we can understand how its afferent discharge, or its central effects, can be affected by disease of the central nervous system. It is also necessary to mention that the muscle spindle is not the only proprioceptor within muscles: the Golgi tendon organ is well represented in all skeletal muscles, but, unlike the primary spindle afferents, its discharge inhibits the motoneurone pool of the muscle within which the discharge originated.

Muscle spindles are encapsulated organs containing intrafusal muscle fibres which carry two distinct sensory organs. Though known since the I86os, it has only recently been recognised that human muscle spindles contain two distinct types of muscle fibres (Cooper \& Daniel, I956), and the same has been shown to be true for the cat (Boyd, I956) (fig. 3). The larger diameter intrafusal muscle

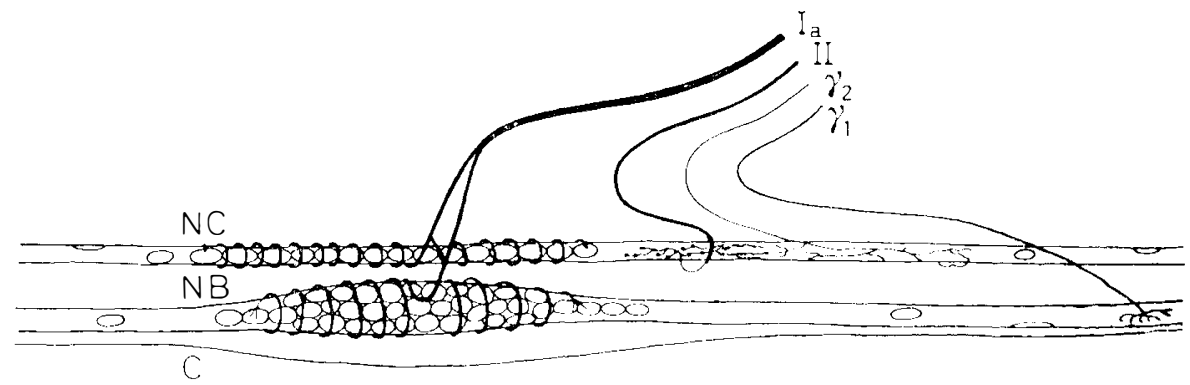

FIG. 3

The innervation of a muscle spindle. Very diagrammatic. Two representative intrafusal muscle fibres are shown. NC-nuclear-chain fibre. NB-nuclear-bag fibre. C-capsule of the spindle. Sensory fibres Ia to primary endings, II to secondary ending. The motor innervation of the nuclear-chain fibre is through $\gamma-2$ motor nerve fibre terminating as a 'trail' ending on the myotube region. The nuclear-bag fibrre is supplied by a $\gamma$-I motor nerve fibre which ends in an end foot in the polar region. From Rushworth, G. (1964). The pathophysiology of spasticity. Proc. roy. Soc. Med. 57, 71 5.

fibres (about $25 \mu$ ) - of which there are only two or three within the spindletraverse the whole length of the spindle and extend beyond the limit of the capsule. They take origin on the endomysium of extrafusal muscle fibre and are inserted into the tendon. Thus they have an 'in-parallel' arrangement with the extrafusal muscle fibres. In the central region the fibres lose their striations and become swollen by a collection of nuclei called the nuclear bag, and it is this region which 
carries the primary sensory ending-an annulo-spiral arrangement which conducts impulses to the spinal cord along the fastest possible afferent fibres (Ia afferents, I 2-20 $\mu$ diam.). The nuclear-bag intrafusal muscle fibre has its own motor supply through small myelinated fibres (stem fibres 4-8 $\mu$ diam.) (Boyd et al., I964), which we term gamma I fibres. These terminate in distinct motor-end plates in the polar region of the nuclear-bag fibres.

The second type of intrafusal muscle fibres are the nuclear-chain fibres, of which there are usually 4-8 per spindle (often more in the human), are of smaller diameter (about I $2 \mu$ ) than the nuclear-bag fibres, and they are confined within the capsule region. They take origin on the perimysium of the nuclear-bag fibres and terminate in the same tendinous bundle, so that they have an 'in-parallel' arrangement with the nuclear-bag fibres. In the central region these fibres contain a chain of nuclei, and it is around this region that the primary ending is wound. This ending appears to be similar to that on the nuclear-bag fibre and it conducts impulses to the same Ia afferent fibre. In addition, the nuclear-chain fibre carries a secondary ending in the myotube region. This transmits impulses to a Group II afferent fibre (6-IO $\mu$ total diam.) and thence to the spinal cord.

The motor innervation of the nuclear-chain fibre terminates in this same region as the secondary sensory ending. The motor fibres are derived from small myelinated fibres ( $\mathrm{I}-4 \mu$ diam.) - gamma-2 fibres, and they terminate in thin axon trailing along the muscle fibre ('trail' endings).

In I 924 Walshe showed that, when dilute procaine was injected into the motor points of muscles in patients with Parkinsonian rigidity or spasticity, the resistance to stretch rapidly melted away, though voluntary power was unimpaired. Liljestrand and Magnus (I9I9) had shown a similar phenomenon in the decerebrate cat.

The effect of procaine was considered to be one of simple deafferentation, and it was believed that procaine blocked large sensory fibres before large motor. Matthews and I (1956, I957a, b) thought that this explanation was wrong. We showed that large sensory and large motor nerve fibres were fairly resistant to the action of procaine, but that when they blocked they tended to block more or less together-though, in fact, the large (alpha) motor fibres were slightly more sensitive to procaine than were large sensory fibres. Small nerve fibres were preferentially blocked by dilute procaine.

When very dilute procaine was applied to the nerve to soleus in a decerebrate cat, the tonic and then the phasic stretch reflexes were rapidly abolished, though the maximal motor twitch or tetanus (as tests for alpha motor nerve integrity) evoked centrally, to the partial block, was completely unaffected (fig. 4). This effect was believed to be due to the selective blocking of gamma motor fibres by procaine-and thus the muscle spindles were made much less sensitive to stretch. In another series of experiments (Matthews \& Rushworth, I958) in which the muscle-spindle discharge was recorded, we showed that, in fact, procaine did greatly reduce the response of the muscle spindle to stretch.

The hyperactive stretch reflexes of the decerebrate cat were thus very dependent on the gamma motor innervation of muscle spindles.

Using different methods, Granit (1955) found that in the decerebrate cat the gamma motoneurones discharged continuously, and the hyperactive musclespindle responses were attributable to this. 
In man, the injection of dilute procaine, either into the motor points of muscles or around major nerves, resulted in the local abolition of the resistance to muscle stretch in both spasticity and Parkinsonian rigidity, without causing any decrease of voluntray power (Rushworth, I960, I96I). The muscle responses were recorded

\section{BEFORE DURINC AFTER}

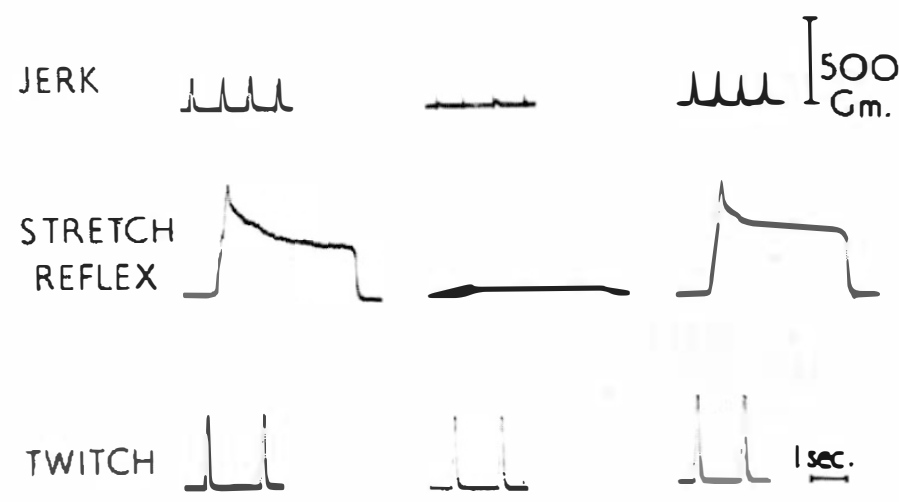

FIG. 4

Records of tendon jerk, stretch reflex and maximum motor twitch of the soleus muscle of a decerebrate cat. Before 0.2 per cent. procaine applied to the nerve. Following application of procaine to the nerve distal to the stimulating electrodes (During), the stretch reflexes are abolished, but the maximum motor twitch is unaffected. After washing away the procaine the stretch reflexes are restored to their previous level. (From 'The role of the gamma system in movement and posture', by Boyd, I. A., Eyzaguirre, C., Matthews, P. B. C., and Rushworth, G. (1964). New York: Association for the aid of crippled children.)

either as tension or electromyographically (fig. 5). Parkinsonian rigidity was more rapidly blocked than was spasticity, and in the spastic muscle the resistance to slow stretch (almost equivalent to the static stretch reflex) was the first to disappear, the tendon jerk disappearing later. Sometimes, during the first stage of the block, the tendon jerks become much larger than before the block was begun, showing that there is either a reciprocal relationship between the phasic and static stretch reflex or that the phasic reflex can be occluded by excessive static stretch reflex activity. The situation, then, appears very similar to the decerebrate cat, and we would postulate that, in both human spasticity and rigidity, muscle-spindle responses are particularly hyperactive, probably due to gamma motoneurone discharge. The increased phasic stretch reflexes which particularly characterise spasticity (fig. 6) I would postulate are due to overactivity of gamma-I motoneurones especially of antigravity muscles, and that overactivity of gamma-2 motoneurones is responsible for any increase of static stretch reflex activity. As gamma2 motor fibres are of smaller diameter than gamma-I, they would be expected to be more sensitive to procaine, and this might explain the observation of the early 


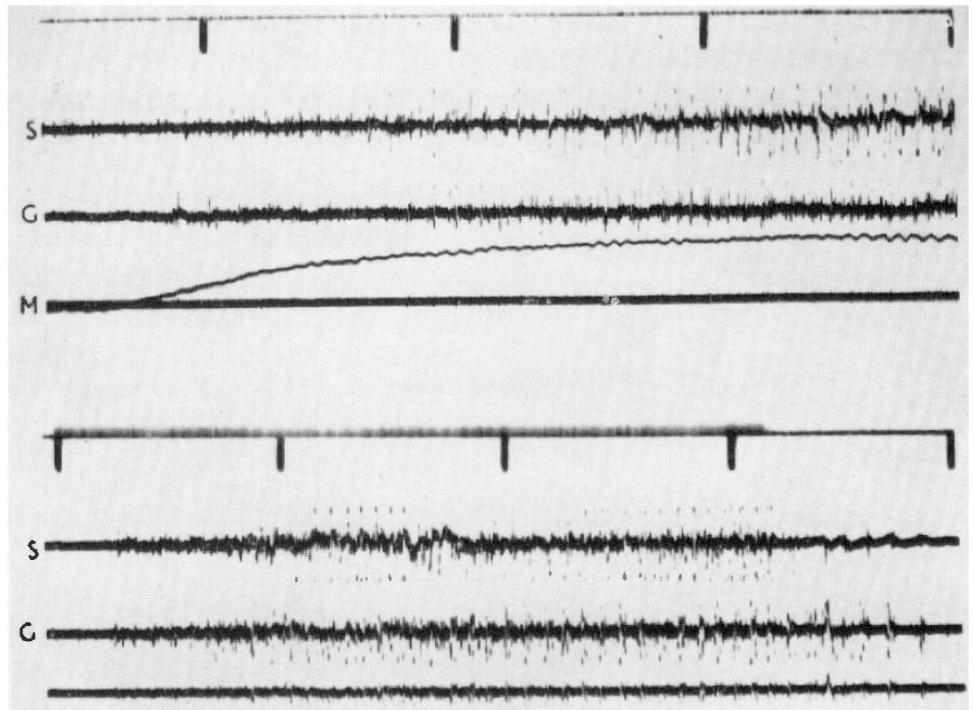

(a)

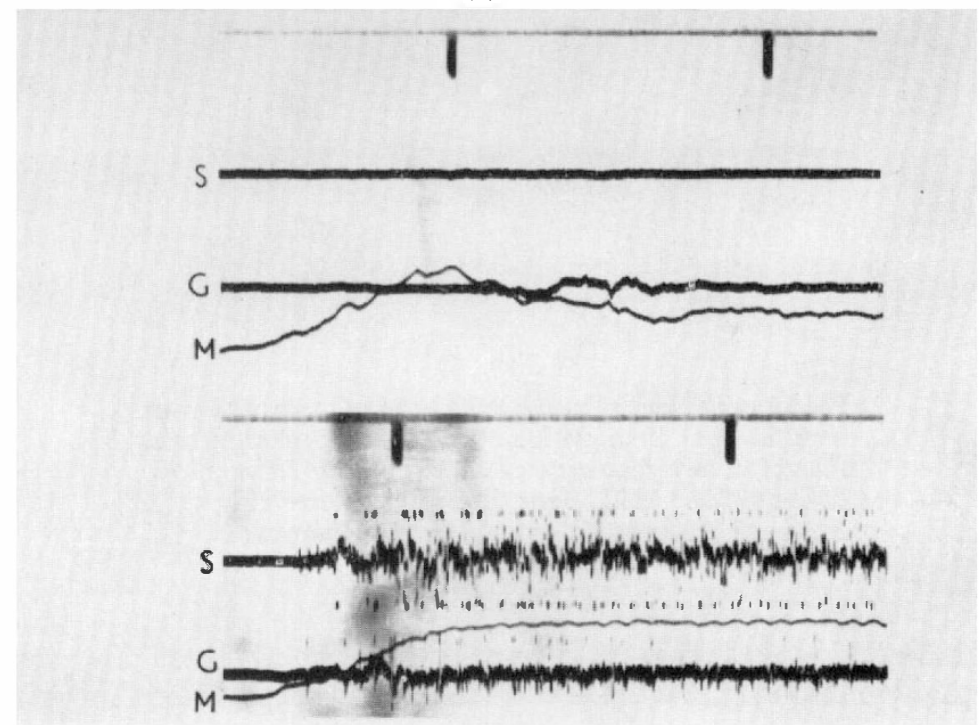

(b)

FIG. 5

Electromyograms from Soleus (S) and Gastrocnemius (G) of a patient with a familial spastic paraparesis. The mechanogram (M) signals muscle stretch. (a) Upper record: response of these muscles to stretch. Lower record: the response to maximal voluntary effort of plantar flexion. (b) A few minutes after injecting I per cent. procaine around the sciatic nerve. The stretch reflexes are abolished, but the muscle still responds to maximum voluntary effort. (From Rushworth, G., I960.) 
abolition of the resistance to slow stretch. In Parkinsonian rigidity, I would postulate that the disordered function lies in the excessive activity of gamma-2 motoneurones, but that, in addition, there are changes in interneurone excitability such that Golgi tendon organs inhibition is more effective on the motoneurone pool. This effect has indeed been demonstrated in the cat by Eccles and Lundberg (1959). The alternation of stretch reflex and lengthening reaction would give plasticity to the muscular rigidity.

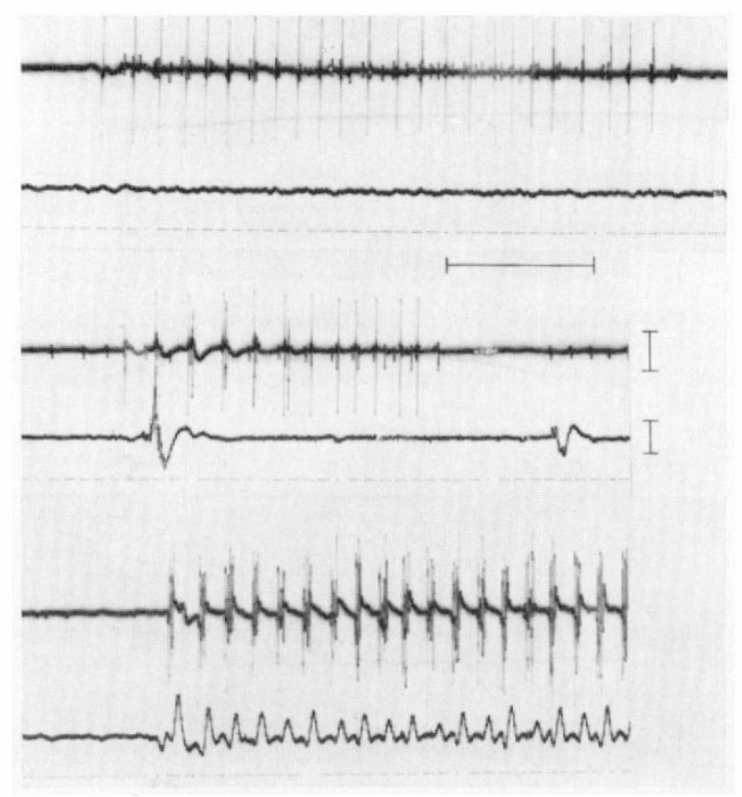

FIG. 6

Electromyograms from lateral head of gastrocnemius (upper line) in a patient with spastic paraparesis. Progressively faster rates of stretching from above downwards. With very fast rates of stretching the response becomes clonic. (From Rushworth, G., I964.)

Dr. Robert Young and I have tried another method of studying muscles spindle activity in man. We have stimulated muscle spindles in gastrocnemiu and soleus muscles under as strictly isometric conditions as possible in man, and have observed the effect on muscle tension and on the ankle jerk and H-reflex (Rushworth \& Young, 1966). In the majority of normal subjects vibration at IOO/sec. results in rapid inhibition of both tendon jerk and $\mathrm{H}-$ reflex, then muscle tension begins to mount slowly. Tendon jerks and $\mathrm{H}$-reflex can be recalled by Jendrassik's manœuvre, even when muscle tension is well advanced. On stopping the vibratory stimulus, the muscle tension quickly declines, but the ankle jerk and H-reflex may take many seconds to return to their previous level.

It is well known, from experiments in the cat, that vibration preferentially 
excites primary muscle-spindle endings (Bianconi \& van der Meulen, I963), which discharge along Ia fibres. Both phasic and static spindle responses of muscle spindles are fed into the same common Ia fibre (Jansen \& Matthews, I963), so that it seems very likely that the spinal cord must differentiate the functional significance of these discharges. A single Ia discharge, or a high-frequency volley of very short duration, will excite the phasic reflex, but it is followed by a long subnormal period, largely inhibitory. A long-continued discharge will excite the static reflex and inhibit the phasic.

We would therefore re-emphasise the functional separation of phasic and static reflexes in man. In preliminary studies in patients with spasticity we find that vibration evokes no rise of tension though both ankle jerk and $\mathrm{H}$-reflex are inhibited as before.

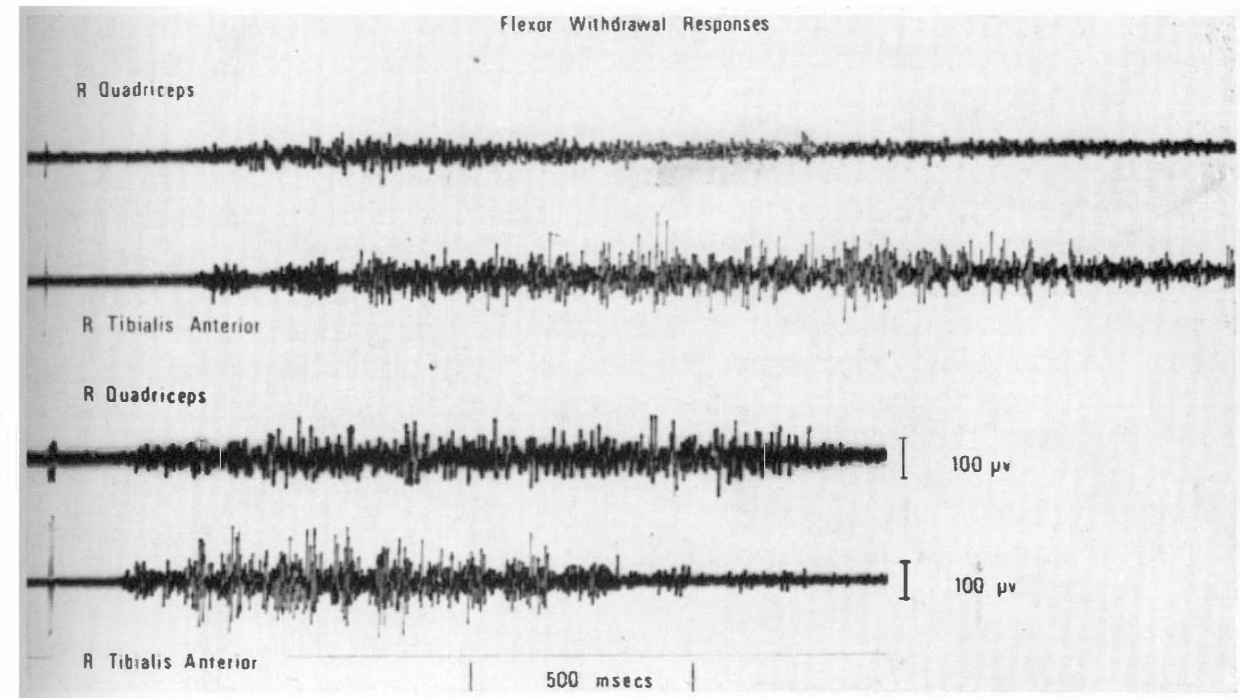

FIG. 7

Electromyograms from quadriceps and tibialis anterior of a patient with flexor spasms. Single shock applied over flexor surface of ankle, upper record, produces response after a delay of about $600 \mathrm{msec}$. A short burst of stimuli reduces the latency to about $240 \mathrm{msec}$., and this cannot be further reduced by high-intensity bursts.

Finally, a few words about flexor spasms, for this heightened reflex activity may accompany flexor spasticity and is a prominent feature of severe lesions of the spinal cord itself.

Acute complete spinal transection in the cat produces, after a short period of spinal shock, flexor reflexes in response to noxious stimulation. Hagbarth (1952) showed that these were locally organised so that the stimulation site determined the pattern of the response and, in addition, stimulation of the skin over extensor muscles excited these muscles producing ipsilateral extension particularly in the standing position, so that balance was maintained. The same organisation was shown for man in the standing position (Hagbarth, 1960; Hagbarth \& Finer, 1963). 
By recording electromyographically from muscles such as tibialis anterior or quadriceps, it could be shown that the application of a sudden painful stimulus (a brief series of electric shocks) to the sole of the foot was followed, about 60 msec. later, by an initial response of flexor muscle, and at about $150 \mathrm{msec}$.by another larger and more prolonged response which was very susceptible to anticipation or to habituation. The early response was certainly a purely spinal reflex, but the second response at 150 msec., which is about the reaction time, was thought to have a cerebral component because of its long latency and because of its regular variations in size by suitable conditioning procedures.

In flexor spasms, it is now clear that the local organisation of the flexor response is destroyed. Stimulation of the skin over an extensor muscle does not excite this muscle and inhibit its antagonists, for the only response appears to be total flexion at all joints. In addition, the latency of these flexor responses is extremely prolonged, beginning about $240 \mathrm{msec}$. from the onset of the stimulus. It is clear, then, that flexor spasms are not just heightened flexor reflexes, for their latency bears no relation to the true spinal flexor reflex.

In normal man, it is impossible to evoke a flexion reflex with a single brief high intensity shock, and a small train of ten or so stimuli, lasting for about 20 msec., is necessary. In flexor spasms a single electrical stimulus can excite a flexor response, but the latency may be prolonged to about $\frac{1}{2}$ second. By increasing the number of stimuli the latency decreases to a minimum of about $200-240 \mathrm{msec}$.

A study of the disordered motor function following central nervous system disease can be made by electromyographic analysis of a number of reflexes, either proprioceptive or nociceptive, for their results may have considerable bearing on the assessment of the functional capacity of the damaged nervous system, and may give other clues to therapy or rehabilitation. The injection of dilute alcohol into the motor points of spastic muscles, the injection of alcohol intrathecally, and of phenol, are all therapeutic attempts based on some of the experimental work outlined above.

\section{REFERENCES}

Bianconi, R. \& van der Meulen, J. P. (1963). F. Neurophysiol. 26, i77.

Boyd, I. A. (1956). F. Physiol. 133, 35 P.

Boyd, I. A., Eyzaguirre, C., Matthews, P. B. C. \& Rushworth, G. (1964). The Role of the Gamma System in Movement and Posture. New York: Association for the aid of crippled children.

Cohen, L. A. (1953). f. Neurophysiol. 16, 272.

Cooper, S. \& Daniel, P. M. (I956). F. Physiol. 133, i P.

Denny Brown, D. \& Liddell, E. G. T. (1927). F. Physiol. 63, I44.

Eccles, R. M. \& Lundberg, A. (1959). F. Physiol. 147, 565.

FOERSTER, O. (I9II). Lancet 2, 76.

Granit R. (1955). Receptors and Sensory Perception. London: Oxford University Press.

Granit, R., Holmgren, B. \& Merton, P. A. (1955). F Physiol., 130, 213.

Hagbarth, K. E. (1952). Acta physiol. scand. 26, Suppl. 94.

Hagbarth, K. E. (1960). F. Neurol. Neurosurg. Psychiat. 23, 222.

Hagbarth. K. E.\& Finer, B. L. (1963). In: Progress in Brain Research, Vol. I p. 65. Ed. Moruzzi et al. Amsterdam: Elsevier.

Jansen, J. K. S. \& Matthews, P. R. C. (1962). F. Physiol. I6I, 357.

Liljestrand, G. \& Magnus, R. (1919). Pflïg. Arch. ges. Physiol. 176, 68.

Matthews, P. B. C. (1962). Quart. F. exp. Physiol. 47, 324.

Matthews, P. B. C. \& Rushworth, G. (I956). F. Physiol. I3I, 30 P.

Matthews, P. B. C. \& Rushworth, G. (I957a). F. Physiol. 135, 245. 
Matthews, P. B. C. \& Rushworth, G. (I957b). F. Physiol. 135, 263.

Matthews, P. B. C. \& Rushworth, G. (1958). F. Physiol. 140, 42 I.

Pollock, L. J. \& Davis, L. E. (I923). Arch. Neurol. Psychiat. I0, 39I.

Pollock, L. J. \& Davis, L. E. (I930). F. comp. Neurol. 50, 377.

Rushworth, G. (1960). F. Neurol. Neurosurg. Psychiat. 23, 99.

Rushworth, G. (I96I). Int. F. Neurol. 2, 34.

Rushworth, G. \& Young, R. R. (1966). ' f. Physiol. (in the press).

SHerRington, C. S. (1893). Philos. Trans. 184B, 63I.

Sherrington, C. S. (1898). F. Physiol. 22, 3 I9.

WALSHE, F. M. R. (1924). Brain, 47, I59.

\title{
FLEXION REFLEX AND STRETCH REFLEX IN SPASTICITY
}

\author{
(A Trial with a Polysynaptic Inhibitor) \\ By G. M. Pool, M.D. \\ Zuiderziekenhuis, Rotterdam
}

Introduction. On the basis of the functional organisation of the spinal cord, there are two reflex patterns (Harpuder, 1962):

I. the stretch reflex, subserving posture, and maintenance of posture in locomotion;

2. the general flexion reflex, subserving withdrawal and protection against injury.

The stretch reflex (fig. I) originates in the annulo-spiral ring of the muscle spindles which lie in parallel with the main muscle fibres and participate in their attachments. The spindle afferent connects by single synapse with the motoneuron innervating the main muscle fibres. The spindle afferents are inhibited by active muscle contraction, activated by passive stretch. By way of the socalled spindle loop, the muscle shortens reflexly until it has shortened to the same extent as has the spindle. The spindle discharge depends not only upon stretch but also upon the innervation which regulates the sensitivity of the spindles. This innervation is for the most part by small fibres of the so-called gamma system and controlled by the reticular formation and further on by higher centres.

Of the polysynaptic reflexes, the polysynaptic flexion reflex plays an important role in the walking action, having its receptive field on the skin of the sole of the foot. Stimulation of sufficient strength of this area causes a co-ordinated withdrawal action with flexion in knee and hip, and extension of the contralateral leg.

In the walking action there is an exact interplay

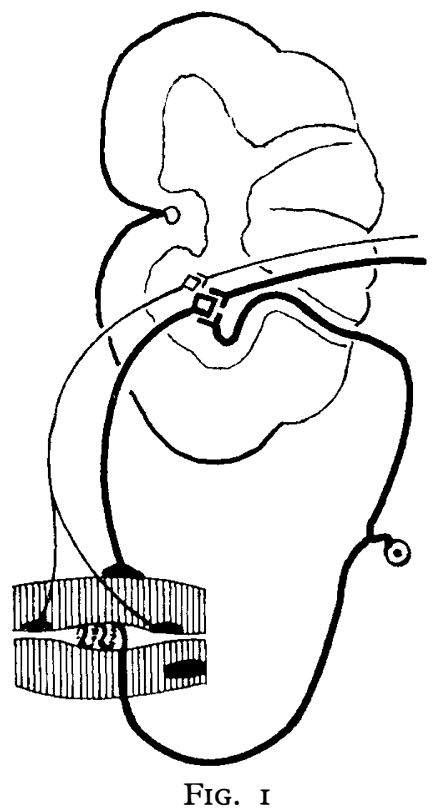

